\title{
UN MODELO DE BIENESTAR Y DESARROLLO INTEGRAL Y SUS IMPLICACIONES PARA LA PRÁCTICA DEL PROFESIONAL DE AYUDA
}

\author{
Raúl Quiñones Rosado* \\ Esterla Barreto Cortez**
}

\section{Introducción}

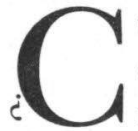

uál es el estado en que se encuentra la sociedad puertorri queña? ¿Cuál es nuestra condición como pueblo, como se res humanos? Como individuos, ¿gozamos de un alto nivel de salud física y mental, una alta calidad de vida? Como colectivo, ¿se están desarrollando plenamente nuestras instituciones políticas y económicas, nuestras organizaciones cívicas, nuestras comunidades? ¿Están en un proceso de evolución verdadera nuestra cultura, nuestro espíritu, nuestra conciencia humana? ¿Acaso tenemos, los que nos dedicamos al bienestar y desarrollo, una noción clara de lo que es el bienestar y el desarrollo pleno, o entendemos cuáles son las condiciones necesarias para encaminarnos hacia ello?

El modelo integral de bienestar y desarrollo humano que compartimos a continuación puede ser muy útil al profesional de ayuda. A diferencia de modelos y teorías que enfocan el bienestar y desarrollo humano en la dimensión individual éste considera la dimensión colectiva y las fuerzas económicas, políticas, sociales y

\footnotetext{
*Co-director ILE: Institute for Latino Empowerment, Aguas Buenas, Puerto Rico

**Catedrática Auxiliar, Escuela Graduada de Trabajo Social, Universidad de Puerto Rico
} 
culturales en que vivimos. Al profundizar en la definición del concepto de integridad el modelo facilita un entendimiento más abarcador sobre lo que es nuestro bienestar y desarrollo individual y colectivo. Como resultado se ha creado un modelo que es:

- Una visión de lo que es el bienestar y desarrollo integral individual y colectivo.

- Una guía para facilitar el análisis crítico de las dinámicas y circunstancias -en nosotros y en nuestra sociedad- que limitan nuestro bienestar y desarrollo integral.

- Una guía para facilitar y dirigir procesos de sanación y transformación individual y colectiva.

En este artículo buscamos describir un modelo que hemos estado desarrollando y utilizando en nuestro trabajo de concientización, principalmente a través de ILÉ: Institute for Latino Empowerment, y Taller Coaí: Círculo de Trabajo para la Conciencia y Acción. Estas son dos organizaciones, de las cuales somos integrantes, que se dedican a la concientización, al desarrollo de liderato y a la organización comunitaria desde una perspectiva de anti-opresión. ILÉ hace su trabajo en comunidades latinas en los Estados Unidos, mientras que Taller Coaí opera aquí en Puerto Rico. Ambas ofrecen talleres, presentaciones, consultorías y asesoramiento principalmente dirigidos al desarrollo de individuos, grupos, organizaciones y comunidades oprimidas. Sus integrantes-fundadores son, a su vez, organizadores comunitarios y están activamente envueltos en luchas locales, nacionales e internacionales en contra del racismo, el sexismo, la homofobia, el colonialismo y el militarismo.

Este modelo de bienestar y desarrollo integral es una integración de varias influencias culturales (indígenas, africanas, asiáticas y anglo-, africano- y latino-americanas) y de varios modelos, teorías y filosofías en las ciencias sociales (Akbar, Ani, Assajeoli, Fanon, Freire, Martín-Baró, Memmi, Montero, Quiñones Rosado, Wilbur, entre otros) y el mismo está aún en proceso. Dadas las limitaciones de espacio en esta publicación, aquí solo compartiremos tres de los modelos que la integran. Estos son:

- La Rueda Medicinal

- El ciclón de la opresión

- El espiral de la transformación 
En la segunda parte de este trabajo compartiremos algunas de las implicaciones del modelo a la práctica del profesional de ayuda en los campos del trabajo social, la psicología y las profesiones aliadas a la salud.

\section{UN MODELO DE BIENESTAR Y DESARROLLO INTEGRAL}

\section{La Rueda Medicinal}

Esta conceptualización de la Rueda Medicinal viene a nosotr@s a través de la tradición nativo-americana de los Lakota. ${ }^{1}$ La "rueda" es un concepto compartido por muchas culturas indígenas, asiáticas y africanas a través del mundo. Provee una visión de mundo amplia y mucho más relevante a nuestra realidad que los modelos contemporáneos de salud, bienestar y desarrollo de origen europeo (Bopp, et.al., 1988).

En la rueda se representan tanto la dimensión individual como la colectiva del ser humano, y se entiende que estas dos dimensiones coexisten en una relación dinámica: el individuo existe y se desarrolla dentro del colectivo; el colectivo se forma a base de los individuos que lo componen.

Pero, veamos primero la dimensión individual.

\section{La dimensión individual}

Al centro de la dimensión individual de la Rueda Medicinal (Ver Ilustración \# 1) encontramos los elementos de:

- la conciencia - la capacidad de percibir y enfocar la atención

- la voluntad - la habilidad de actuar con intención y dirección

${ }^{1}$ Le damos reconocimiento y agradecimiento especial a la Dra. Lenore Stiffarm, Four Worlds Development Project, University of Lethbridge, Alberta, Canada, y el pueblo Lakota de Norteamérica, por compartir con nosotr@s la sabiduría de "la rueda medicinal". 


\section{Ilustración 1 \\ La Rueda Medicinal}

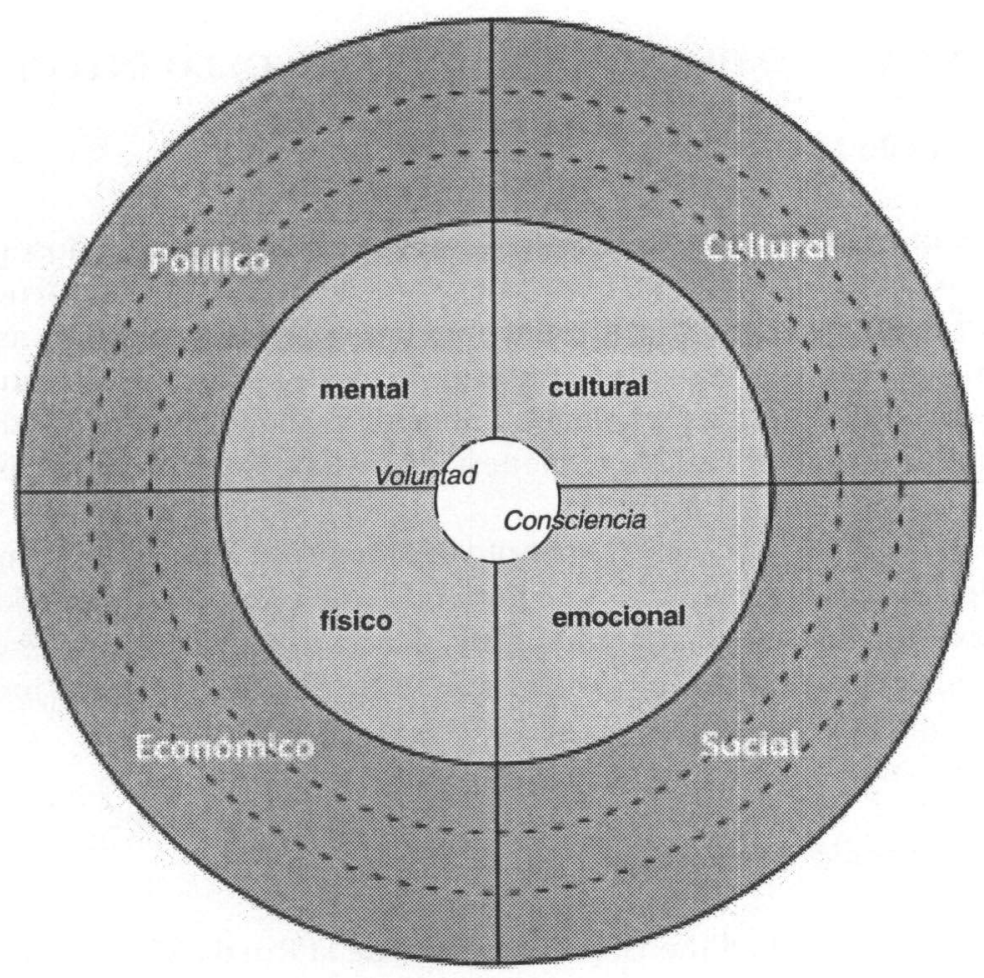

Dimensión individual

Dimensión colectiva: grupos, comunidad-organización, nación. 
La conciencia y la voluntad son elementos esenciales de nuestra existencia y así como el ying/yang del Tao o el ibeji Yoruba son aspectos de nuestro ser complementarios el uno del otro. Uno no puede existir sin el otro (Assigioli, 1973, 1976; Wilbur, 1977).

Juntos, nuestra conciencia y voluntad son los que nos permiten utilizar los cuatro aspectos de nuestro ser personal para hacer sentido de nuestra experiencia, de nuestra existencia y del mundo que nos rodea; nos permiten sopesar opciones y tomar decisiones, y finalmente, tomar acción. La conciencia y la voluntad son los vehículos mediante los cuales utilizamos nuestros recursos internos de los cuatro aspectos de la dimensión individual para lograr bienestar y desarrollo pleno.

Los cuatro aspectos de esta dimensión de la Rueda Medicinal son:

- El aspecto físico - se refiere a nuestro cuerpo, con todas sus funciones fisiológicas, el cual nos permite interactuar directamente en y con el mundo.

- El aspecto mental - se refiere al intelecto, la habilidad de razonar, de buscar y encontrar soluciones a problemas. También envuelve la creatividad y la imaginación. La mente, con todas sus capacidades cognoscitivas y creativas, es lo que nos permite darle nombre y forma al mundo.

- El aspecto emocional - se refiere a nuestra parte afectiva, a nuestros sentimientos y deseos. Las emociones, el corazón, nos facilitan la interacción con otros individuos, y son también claves en el aprendizaje y para la sobrevivencia misma.

- El aspecto espiritual - se refiere a nuestra capacidad de intuir, de sentirnos íntimamente ligad@s y conectad@s con otros seres, con el planeta, y con una fuerza y/o conciencia transcendental universal. También tiene que ver con nuestros valores, principios, convicciones y propósito o razón de ser.

Es importante tener presente que estos cuatro aspectos están íntimamente relacionados y son inseparables. Como en todo modelo conceptual, las divisiones presentadas gráficamente aquí son, en realidad, artificiales y arbitrarias. Estos aspectos, como los de la dimensión colectiva que presentaremos posteriormente, coexisten más bien de forma holográfica, el uno intrínsecamente ligado y 
contenido dentro del otro. O sea, en el ser humano, la mente y las emociones no existen independientemente de los procesos bioquímicos y eléctricos del cerebro, el cual a su vez depende de otras múltiples y complejas funciones del cuerpo. Y como muchos afirman, la vida corporal, con mente y emociones, no existe sin el espíritu.

Dentro del modelo de la Rueda Medicinal, el bienestar y el desarrollo de una persona se logran a través de un proceso continuo de nutrir y desarrollar cada uno de los aspectos del individuo. $\mathrm{O}$ sea, el bienestar se da en la medida en que se nutren el cuerpo, la mente, el corazón y el espíritu. Para el bienestar integral, por ende, es necesario el equilibrio: que el desarrollo ocurra de forma balanceada, que se le preste la atención necesaria a todos los aspectos. Por ejemplo, no podría darse el bienestar pleno en una persona que atiende principalmente su desarrollo intelectual mientras desatiende su cuerpo, digamos por la falta de una buena alimentación y/o ejercicio, o por el abuso de sustancias adictivas, o su vida emocional, digamos con relaciones afectivas superficiales, y a expensas de su vida espiritual digamos, desatendiendo un supuesto compromiso con valores como el amor, la belleza, el servicio, la justicia.

El principio del equilibrio, o la homeostasis, es fundamental en el bienestar integral. Pero hay que recordar que éste es un proceso de continuo movimiento, una búsqueda constante de algo que nunca se alcanza plenamente, ya que el logro del balance perfecto envolvería stasis, falta de movimiento, muerte.

Igualmente importante en el proceso de bienestar es el principio de la armonía. Esto se refiere a la congruencia entre los cuatro aspectos de la dimensión individual. En este principio se afirma la necesidad de que halla consistencia entre nuestras conductas (el aspecto físico), nuestras ideas y creencias (el aspecto mental), nuestros sentimientos (el aspecto emocional), y nuestros valores (el aspecto espiritual). Es el principio recogido en la expresión popular, “Practica lo que predica”. En otras palabras, un@ lucha para resolver las contradicciones o los conflictos entre los aspectos mentales, emocionales, físicos y espirituales en la vida de un@.

Juntos, los principios de equilibrio y armonía nos llevan a otro principio clave en el proceso de bienestar: la integridad. Aquí el concepto de integridad tiene varias connotaciones. Uno se aproxima al concepto matemático del íntegro, uno, la unidad, la unión de partes potencialmente fragmentadas. Otra connotación es la que se 
usa popularmente para referirse a aquella cualidad de la persona de carácter intachable. Aun otra se refiere al concepto arquitectónico, la "integridad estructural", que se refiere a la fortaleza sinergética obtenida de la colocación estratégica y precisa de los diferentes elementos de construcción.

Esta integridad, unidad libre de fragmentación, esta cualidad de carácter intachable, esta sinergía, le da a la persona una fortalezafísica, mental, emocional, y espiritual-para conducir su vida. Lleva a la persona a sentirse más completa, genuina y honesta consigo mism@, más libre de conflictos internos y de contradicciones. Integridad, en este sentido más amplio y profundo de la palabra, es la base de lo que llamamos: poder personal, poder auténtico o poder transformativo y es esta la fuente del verdadero liderato transformativo.

En este proceso la conciencia y la voluntad son elementos esenciales ya que es a través de nuestra capacidad de conciencia propia y la habilidad para dirigir nuestras acciones que podemos crear cambios en nuestras vidas. Nuestra conciencia nos permite entender nuestros conf lictos internos mientras nuestra voluntad nos permite hacer las acciones correctivas necesarias. De esta manera reconocemos y utilizamos los recursos internos en cada uno de los aspectos de nuestro ser con el fin de promover nuestro bienestar y desarrollo personal.

\section{La Dimensión Colectiva}

El bienestar y el desarrollo humano, sin embargo, no se limita al nivel individual. Después de todo, los individuos vivimos en grupos y nos organizamos dentro de unas estructuras que han sido institucionalizadas.

En la Rueda Medicinal, existen cuatro aspectos en esta dimensión colectiva:

- El aspecto económico - tiene que ver con la producción, el manejo y la distribución de los recursos de una sociedad. Aquí nos referimos a la banca, la industria, el comercio, el mercado de valores, la economía "subterránea”, y por supuesto, la fuerza laboral, los desempleados, y los consumidores.

- El aspecto político - se refiere a las leyes y reglas mediante las cuales se rige la sociedad. Incorpora todas las instituciones, 
organizaciones y grupos a cargo de la adopción e implementación de estas leyes y regulaciones. Entre otras, esto incluye el gobierno y sus agencias (incluyendo el aparato militar y sus variados instrumentos) y los partidos y otros grupos políticos.

- El aspecto social - se refiere a la forma en que se organiza la gente (en familias, vecindarios, comunidades, organizaciones, y otros grupos de identidad compartida), y a sus interacciones, tanto a nivel interpersonal como entre grupos.

- El aspecto cultural - se refiere a los valores, creencias, actitudes y conductas compartidas por los miembros de grupos sociales y/o comunidades, y por los integrantes de una sociedad en general. Envuelve las instituciones religiosas y educativas, y los medios de comunicación, entre otras.

Al igual que en la dimensión individual, el equilibrio y la armonía entre todos los aspectos de la dimensión colectiva es crucial al bienestar de una comunidad y a su continuo desarrollo. Por ejemplo, si una comunidad (o subgrupo) tiene una rica vida social y cultural, donde hay música, la gente va a la iglesia y se reúnen en familia, pero tienen problemas de una alta tasa de desempleo y no tienen acceso real a los procesos políticos, los miembros de esa comunidad-como colectivo-no podrán alcanzar su bienestar y desarrollo pleno, y mucho menos ser una comunidad que se auto-determina. De igual forma, si un grupo tiene poder político y económico, pero carece de vida social y desarrollo cultural verdadero, con integridad respecto a sus valores más preciados, vivirán de forma desequilibrada y desarmoniosa-deshumanizada y deshumanizante.

Una premisa clave, aunque obvia, de este modelo es que: mientras mayor sea el nivel de bienestar y desarrollo de una sociedad, mayor será el nivel de bienestar y el potencial de desarrollo de los individuos que la componen. Y simultáneamente, mientras mayor sea el nivel de bienestar y desarrollo de los individuos de una sociedad, mayor será el bienestar colectivo y su potencial de desarrollo y de auto-determinación. En esta visión de mundo, el individuo y su comunidad son totalmente inseparables; verdaderamente dependen el uno del otro para su bienestar y desarrollo.

Así como en la dimensión individual, la conciencia y la voluntad son elementos esenciales en el proceso de alcanzar y mantener el bienestar colectivo y de moverse continuamente hacia su desarrollo 
pleno. Y así como en la dimensión individual, la conciencia y la voluntad colectiva, compartida, utilizados con integridad para desarrollar y mediar los recursos económicos, políticos, sociales y culturales colectivos y para movilizar los recursos mentales, espirituales, emocionales y físicos de sus individuos, es lo que llamamos poder auténtico transformativo colectivo. Este el poder de la verdadera autodeterminación de una comunidad, de una sociedad, de un pueblo.

\section{Las fuerzas que obstaculizan el bienestar y desarrollo de nuestra comunidad}

En un mundo ideal, los individuos y las comunidades deberían poder crecer y desarrollar al máximo sus capacidades, en todos sus aspectos, en ambas dimensiones de acuerdo con la Rueda Medicinal. Sin embargo, sabemos que en el mundo real, hay fuerzas en la sociedad que impactan negativamente, y más aún, obstaculizan la habilidad que tenemos los individuos y las comunidades, y la nación, de crecer y desarrollarnos plenamente. Esto es cierto tanto en Puerto Rico como en casi todos los países del mundo, incluyendo los llamados "países desarrollados".

El análisis crítico de las fuerzas que operan en nuestro país nos llevan a entender que existe un patrón, una dinámica que se manifiesta en todos los ámbitos económicos, políticos, sociales y culturales del quehacer diario. Es una dinámica donde miembros de grupos dominantes subordinan sistemáticamente a miembros de otros grupos con el fin de mantener el acceso al y el control de los recursos de la sociedad. A esa dinámica sistemática de control y dominio le llamamos: opresión institucional. ${ }^{2}$

En el modelo integral de bienestar y desarrollo, estas fuerzas forman un círculo, o una vórtice, alrededor de la dimensión colectiva de la Rueda del Bienestar (Ver Ilustración \#2). A esta dinámica le llamamos el ciclón de la opresión.

2 Muchas de las definiciones relacionadas a la opresión que aparecen en este artículo provienen mayormente de talleres y adiestramientos profesionales en las cuales asistí y no de publicaciones. Las fuentes principales son: Equity Institute, Amherst, MA; The People's Institute for Survival and Beyond, New Orleans, LA; Elsie Y. Cross Associates, Inc., Philadelphia, PA. 


\section{llustración 2 \\ El ciclo de la opresión institucional}

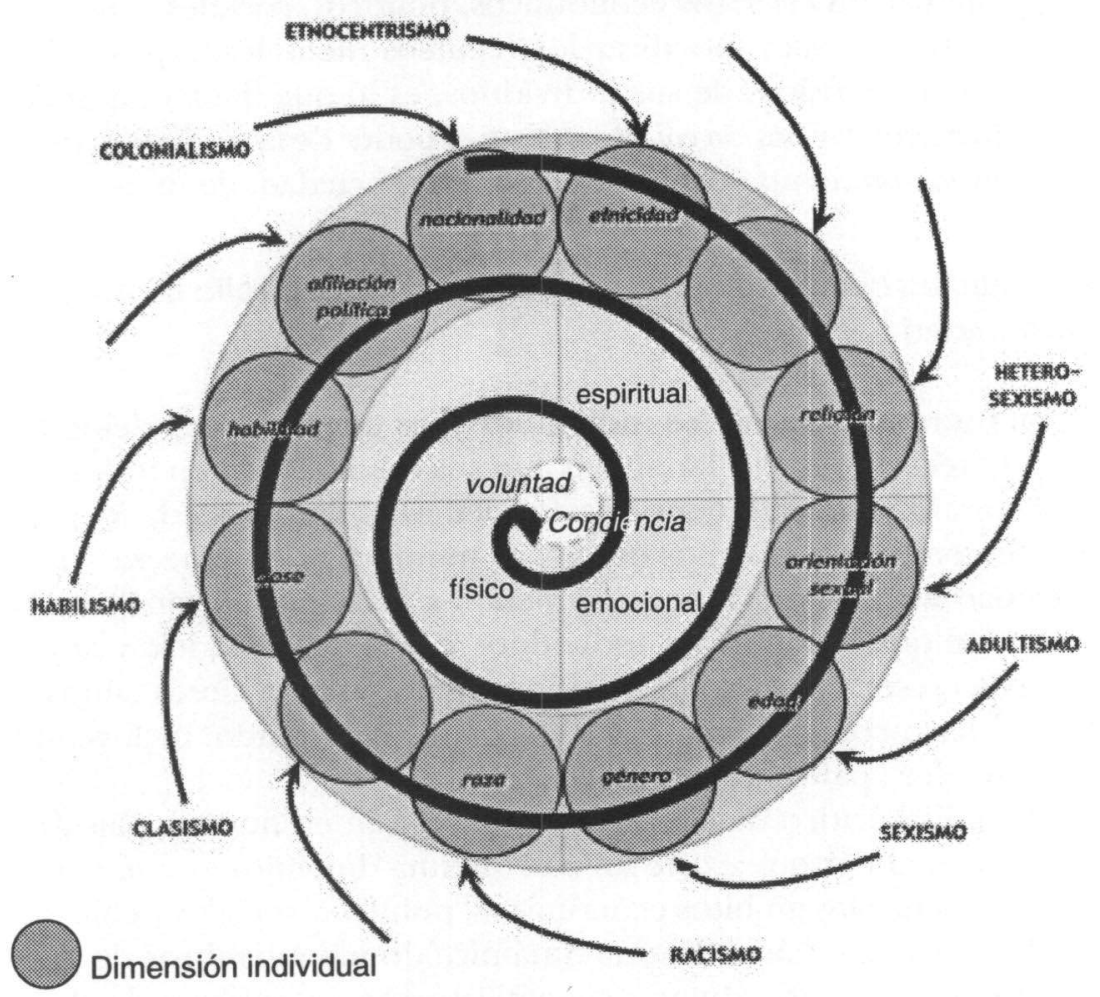

Dimensión colectiva: comunidad, organización, nación.

En la gráfica vemos que la opresión institucional tiene muchas formas, ya que impacta a los miembros subordinados en todas los grupos de identidad social en nuestra sociedad. Entre los grupos de identidad social más significativos figuran: género; clase socio-económica; raza; cultura; orientación sexual; nacionalidad; edad; habilidad (física y mental); religión; y en Puerto Rico, afiliación política.

Al racismo, al clasismo, al eurocentrismo, al sexismo y a las otras formas de opresión que ilustramos aquí se les llama opresión institucional ya que, después de muchas generaciones de ser perpetuados, se han convertido en parte integral de las instituciones de la sociedad (las escuelas, los negocios, las cortes, los medios, etc.). Incluso han sido creadas intencionalmente dentro del sistema legal, económico, educativo, gubernamental, etc., por aquellos que, en primer 
lugar, crearon estas instituciones. Por ejemplo, la esclavitud fue una institución legalmente sancionada, y a pesar de su abolición hace más de cien años, muchas de las actitudes de supremacía blanca perduran en nuestras instituciones culturales y religiosas; ¿de que otra manera se explica la presencia universal en nuestras iglesias de imágenes de Jesucristo, un africano, como una persona de tez blanca, pelo lacio y de ojos claros? ¿ O, a Dios mismo, como hombre y como blanco? Pero, ¿qué es lo que más precisamente define la opresión?

Al definir el tếrmino opresión los educadores comunitarios usualmente utilizan una fórmula muy sencilla:

\section{Prejuicio + Poder $=$ Opresión institucional}

Esta fórmula nos sirve para asegurarnos de que la opresión institucional no sea confundida con los términos prejuicio o discrimen. Prejuicio en este contexto es una serie de creencias negativas en relación a los miembros de un grupo social basado en estereotipos, mitos, desinformación y mentiras. Es un sistema de creencias, no una conducta. Cuando se actúa sobre la base de un prejuicio para lastimar, dominar y/o excluir a alguna persona por ser miembro de otro grupo social (por raza, sexo, etc.) entonces se convierte en discrimen. Cuando esa acción discriminatoria es sancionada por el estado implícita o explícitamente, a través del poder económico, político, social y cultural de sus instituciones, porque mantiene los valores y protege las intereses de aquella en control, entonces es conocido como opresión institucional.

Ofrecemos aquí algunas definiciones en relación a la opresión institucional las cuales son frecuentemente utilizadas por los educadores o abogadores de justicia social:

PODER Acceso legal a y/o control sobre los recursos necesarios para el bienestar y desarrollo.

PRIVILEGio Ventajas, recompensas o beneficios otorgados a miembros de grupos dominantes (con poder).

PREJUICIO Creencias negativas basadas en estereotipos que son generalizadas a todos los miembros de un grupo social.

OPRESIón La subyugación sistemática e institucionalizada de unos grupos sociales por otros grupos con poder económico, político, social y/o cultural; o más sencillamente: opresión $=$ prejuicio + poder 
AGENTES DE Miembros de un grupo social dominante que gozan de OPRESIÓN poder institucional y privilegio sobre miembros del grupo subordinado.

BLANCOS DE Miembros de un grupo social subordinado que no OPRESIÓN tienen poder institucional en relación a un grupo dominante.

ALIADOS

Miembros de grupos dominantes quienes cuestionan los privilegios de los cuales gozan y abiertamente retan la opresión que su grupo comete contra otros.

\section{La opresión internalizada}

Obviamente, no vivimos en una sociedad ideal, una que promueva el bienestar y el desarrollo pleno de nuestras comunidades. Por el contrario, vivimos en una sociedad donde la opresión institucional significativamente menoscava nuestra habilidad de crecer y prosperar, e incluso amenaza nuestra existencia misma como nación.

Sin embargo, al nosotr@s, 1@s profesionales de ayuda, querer influir positivamente la vida de nuestra gente $-\mathrm{y}$ en el proceso, de nuestras comunidades y sociedad en general- es importante recordar que el racismo, el sexismo, la homofobia y otras formas de opresión institucional están muy arraigadas en nuestras propias creencias y actitudes. Los individuos no nacemos creyendo que somos superiores o inferiores a otros. Estas creencias están tan arraigadas porque las aprendemos durante nuestro proceso de socialización; se nos educa a que nos creamos superiores o inferiores; somos entrenados a actuar como si lo fuéramos, y estas creencias, sentimientos y conductas son reforzadas por las reglas escritas y no escritas de esta sociedad.

Como muy bien ilustra la gráfica anterior, los "vientos del ciclón de la opresión” impactan también a la dimensión individual de la rueda, incluso hasta nuestra esencia misma: nuestra conciencia y voluntad. Los individuos nacen en distintos (o varios) grupos sociales que son determinados por su raza, género, cultura, clase social, orientación sexual, etc. Debido a que existen dinámicas de poder y privilegio en esta sociedad, los prejuicios de los grupos sociales que dominan (los blancos, los hombres, los ricos, los heterosexuales, etc.) son sistemáticamente transmitidos a tod@s $1 @ s$ niñ@s en nuestra sociedad. 
Desde el momento en que un/a niñ@ llega al mundo, los padres, las madres, la familia entera y otros allegados le enseñan a este/a los estereotipos, la información incorrecta, la historia distorsionada y los prejuicios sobre los distintos grupos sociales -incluyendo los suyos propios. A veces estas enseñanzas perjudiciales se transmiten de forma consciente y deliberada. Sin embargo, por lo general se transmiten inconscientemente como algo "normal".

A medida el/la niñ@crece, estos mensajes negativos son reforzados por las muchas influencias de la sociedad: los maestros/as, consejeros/as y principales; actores, músicos y personalidades de los medios de comunicación; maestros, religiosos, líderes y feligreses; cajeros, banqueros y jefes; oficiales policiacos, legisladores y presidentes; y en fin muchos otros.

Para el tiempo en que estos niños/as llegan a ser adultos, sus sentimientos de culpa, dolor, miedo y coraje -y la confusión y enajenación que los acompaña - les hace creer que estos mensajes negativos e incorrectos son ciertos. $\mathrm{Y}$ a la vez que una persona cree estos mensajes (o los internaliza), la noción de que algunos grupos sociales son superiores a otros -aún cuando se pertenece a estos grupos- es adoptada como cierta y se empieza a participar en el sistema establecido de dominancia, privilegio, ventaja y poder.

De esta forma, el ciclo de la opresión es continuado y se le impone a otra generación de opresores y oprimidos.

Como profesionales de ayuda es importantísimo que entendamos claramente este concepto de opresión internalizada. Al examinar el Ciclón de la Opresión vemos que la opresión internalizada es el resultado inevitable del entrenamiento sistemático al cual las personas están sometidas en esta sociedad. Consiste en creer o dejarse llevar por los mensajes negativos que han sido propulsados por el grupo dominante sobre nuestro propio grupo social. Por ejemplo: un jefe puertorriqueño de tez clara cree que "todos los negros son vagos", irresponsables y "parejeros", y a base de estos estereotipos les niega empleo, esto constituye opresión racista institucional. Ahora, cuando una persona negra se cree estos mensajes sobre él o ella misma -y a base de esta creencia- ni siquiera solicita empleos para la cual está plenamente capacitada, esto es una expresión de opresión racista internalizada. La persona de este ejemplo fácilmente puede ser sustituida por, digamos, una mujer, una persona gay o lesbiana, una persona pobre, una persona envejeciente, o una 
persona con algún impedimento; solo cambiaríamos el nombre del tipo de opresión internalizada.

La opresión internalizada no es el que una persona se de por vencida porque el sistema le ha fallado, le ha negado lo esencial o le ha victimizado innumerables veces a través de su vida. La opresión internalizada es cuando una persona se da por vencida porque piensa que no tiene valor como persona. Junto al impacto de la violencia que resulta de la opresión institucional (la pobreza y la explotación, la violencia contra la mujer y los niños, la exclusión sistemática, la falta de acceso a una educación adecuada, etc.) La opresión internalizada lleva a las personas oprimidas a dudarse a sí mismas y a desconocer su valor intrínsico como seres humanos. El resultado es un ser humano desconectado de su propia humanidad que perpetúa así la violencia hacia sí mismo/a y hacia los/las demás. En este contexto decir que la opresión nos produce estrés o que deteriora nuestra auto-estima o auto-concepto es una subestimación bárbara de sus efectos. De hecho, la profunda internalización del racismo, sexismo, clasismo y otros mensajes y experiencias opresivos llevan a personas oprimidas a odiarse a sí mismas y a la auto-destrucción (Akbar, 1996, Bulhan, 1985; Fanon, 1963; Hooks, 1995, 1993).

Es particularmente importante que $1 @$ s profesionales de ayuda entendamos bien la opresión internalizada, ya que son precisamente con los síntomas de ésta con las que lideamos en nuestros trabajos. Por ejemplo; para el tiempo que 1@s jóvenesnegr@s puertorriqueñ@s alcanzan la pubertad han escuchado miles de mensajes negativos de boca de los maestros, los compañeros de escuela, la televisión y los policías. Y lo más probable será que ya hayan tenido muchas experiencias negativas por el hecho de ser quienes son y pertenecer a su grupo social. La repetición de estos mensajes negativos les llevan a:

\section{dudarse a sí mismos - baja estima - odio a sí mismos \\ lo cual a su vez se convierte en apatía - desesperanza - bajas expectativas - conducta autodestructiva - violencia ${ }^{3}$}

${ }^{3}$ Le agradecemos el trabajo al colega educador anti-racista Kenneth Jones, Jones \& Associates, Jacksonville, FL, por su trabajo relacionado a la opresión internalizada. 


\section{De la Opresión a la Transformación}

Previamente vimos como el racismo y otras creencias, actitudes y conductas opresivas son aprendidas y pudimos apreciar como las instituciones opresivas de esta sociedad fueron creadas por personas que se benefician de ellas. También dijimos que las personas crecen y pueden cambiar y que la sociedad puede, en efecto, transformarse. Lo que ahora proclamamos es que la opresión -tanto la institucional como la internalizada- puede ser revertida y erradicada; y que el ciclo de la opresión puede ser interrumpido (Ver Ilustración \#3).

\section{Ilustración 3 De la Opresión a la Transformación}

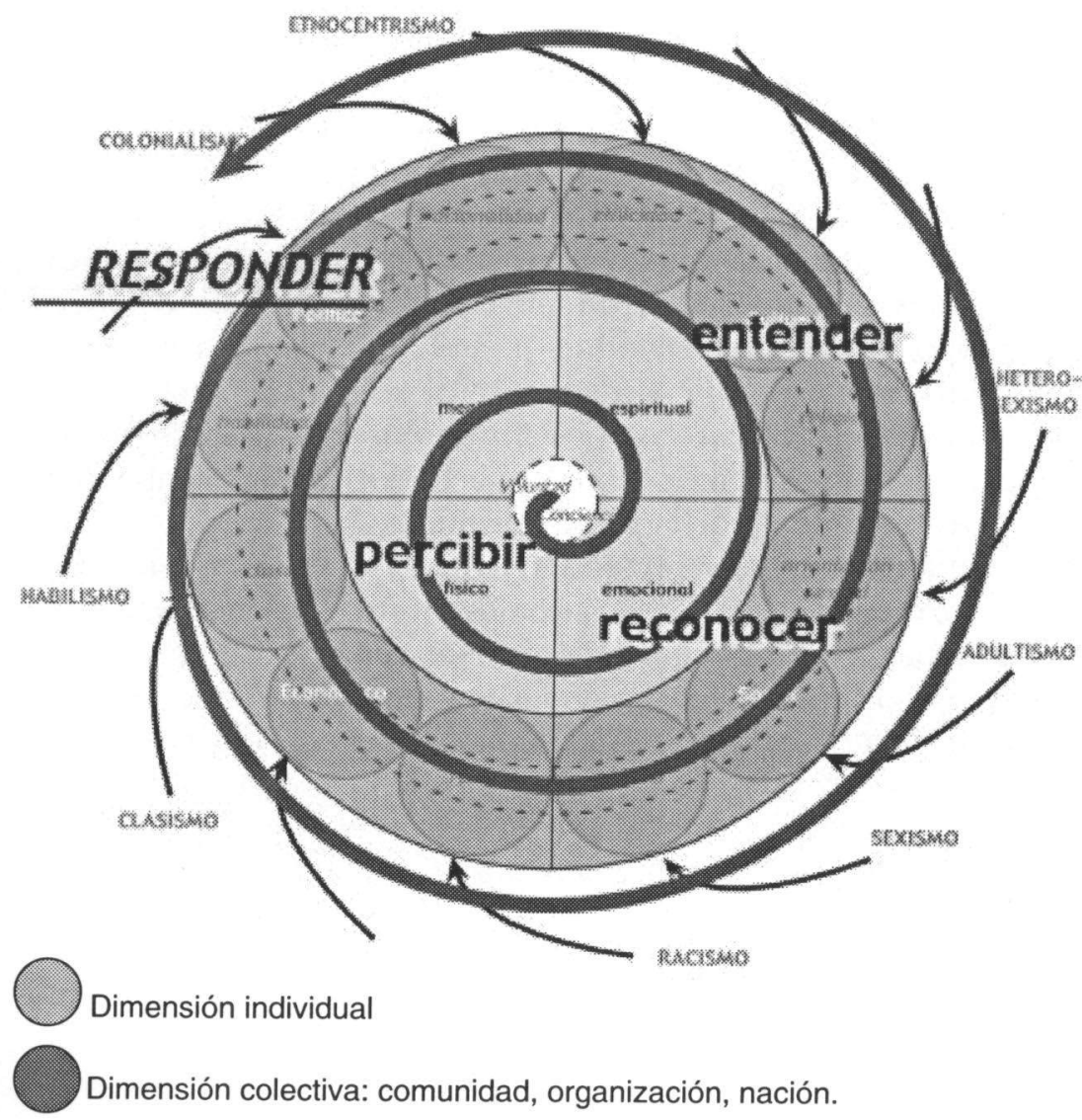


Para que el ciclo de la opresión se interrumpa y se transforme se requiere que los individuos y las comunidades luchen por alcanzar el poder auténtico en sus vidas. Pero es claro, que esto no se puede hacer sin confrontar la opresión institucional e internalizada directamente y con determinación.

La primera etapa de este proceso requiere percibir la opresión: verla, sentirla y percibir su presencia. El percibirla no es una cosa automática. De hecho en muchas ocasiones se necesita mucho entrenamiento para hacerlo, especialmente cuando la opresión es sutil y cuando viene de gente en la cual uno confía. Después de todo, en una cultura donde se valora al individuo más que al colectivo, se nos enseña que si algo no va bien en nuestras vidas es porque estamos haciendo algo mal. Al reconocer la opresión aprendemos que lo que nos pasa a nosotros individualmente le pasa a otros como nosotros.

La segunda etapa de este proceso requiere reconocer la opresión. Esto significa estar dispuesto a mirarla a la cara, sin negarla; estar dispuesto a llamarla por su nombre una vez es percibida y; estar dispuesto a decir "Esto es racismo. Esto es adultismo. Esto es sexismo. Esto es homofobia.” El reconocer la opresión, particularmente en el momento en que ocurre, es bien importante. Una vez se hace esto se siente su impacto y le da a uno un sentido de poder. Sin embargo, por sí solo no conduce a cambios positivos. De hecho, casi siempre le hace sentir a un@ coraje, resistencia y rebeliónespecialmente a los adolescentes y a los hombres jóvenes. De todas maneras, estos sentimientos son una parte crítica e inevitable del proceso de crecimiento de la gente oprimida.

La tercera etapa requiere entender la opresión: el saber como trabaja; el darse cuenta que todos nacemos en una sociedad que nos entrena -tanto al opresor como al oprimido- en el arte infame de la opresión; el verdaderamente entenderlo, y captarlo. Cuando verdaderamente entendemos la opresión, nos damos cuenta que el echarle la culpa a aquellos que nos oprimen, o el sentirnos culpables por haber oprimido a otros, sencillamente, no tiene ninguna utilidad. Sin necesidad de negar los sentimientos de coraje o de culpa, de miedo o de dolor, cuando percibimos, reconocemos y entendemos la opresión, estamos listos para entrar en la próxima etapa.

La cuarta y última etapa requiere responder a la opresión: de forma conciente y deliberada, escoger un camino apropiado de acción, y tomar esa acción con pericia. Sin percibir, reconocer y 
entender la opresión estamos destinados a meramente reaccionar de acuerdo a nuestro entrenamiento social y a la inclinación de nuestra personalidad. Generalmente esto significa que ante la opresión, la aceptamos y nos sometemos, nos escapamos o huimos, o la resistimos y nos defendemos. Sin percibir, reconocer y entender vivimos reaccionando cada vez que nos hunden los botones, así como si fuéramos una computadora último modelo o aún peor como si fuéramos el gatillo de una pistola.

Por lo tanto, responder con conciencia y voluntad es lo que nos permite dejar la conciencia de víctima y adoptar una conciencia de poder auténtico. Porque tenemos la habilidad de ver, nombrar y entender la situación, podemos dejar de responder automáticamente. Podemos igualmente escoger concientemente formas apropiadas y efectivas de lidiar con el racismo, el sexismo y otras circunstancias igualmente opresivas. De esta forma, reclamamos el control de nuestras vidas -y aumentamos las probabilidades de que nuestras acciones conscientes traigan resultados positivos. Este proceso es lo que se conoce como verdadera concientización o conciencia-en-acción o lo que en inglés se llama "empowerment" (Freire, 1970). De acuerdo a este modelo la verdadera concientización comienza en el momento en que concientemente escogemos cómo responder con la forma de opresión con la que nos confrontamos.

\section{IMPLICACIONES DEL MODELO DE BIENESTAR Y DESARROLLO INTEGRAL A LA PRÁCTICA DE PROFESIONALES DE AYUDA Y DE LA SALUD}

Las misiones expresadas en los códigos de ética de las asociaciones de profesionales de ayuda incluyendo proveedores de salud en su mayoría hacen referencia a un compromiso en favor del bienestar de los seres humanos. Algunas, como la de la Asociación Nacional de Trabajadores Sociales (1996), van más allá afirmando su compromiso en la lucha por la justicia social. Sin embargo, estos compromisos han sido más fáciles de declarar en un documento que de ejercer en la práctica. A raíz de éstos han sido múltiples los enfoques e intervenciones que desarrollamos los profesionales de ayuda con la buena intención de propiciar y mantener el bienestar de individuos y colectividades. Inclusive son muchas las ocasiones en las 
que por falta de un análisis sobre las dinámicas de poder y opresión nuestros enfoques e intervenciones contradicen la misión expresada en nuestras declaraciones y juramentos profesionales. Es así como en términos generales podemos identificar "modelos de déficit" que enfatizan en la carencia de individuos y colectivos de capacidades, destrezas, condiciones, genes, habilidades, defensas, capital, recursos, etc. en comparación a individuos y grupos que sí las tienen. Por lo general el grupo "comparación” o "control” -el grupo de los que tienen de lo que los demás carecemos- son hombres, blancos, descendientes de europeos, dueños de capital, heterosexuales, cristianos, con todas sus capacidades físicas y mentales, y todas los otros privilegios que en un sistema opresivo están asociadas a los agentes de opresión (pensemos en Bill Gates o Richard Carrión). Estos enfoques e intervenciones son a los que usualmente nos referimos cuando hablamos de modelos tradicionales en los diferentes campos de ayuda. Tómese por ejemplo en la sicología las terapias de adaptación y cambio de conducta, en el trabajo social los modelos asistencialistas y desarrollistas, y en la medicina el énfasis en la medicalización para combatir síntomas y no la causa que propicia las enfermedades. Estos modelos están basados en enfoques paternalistas que promueven la caridad del que tiene de dar para ayudar aquellos que no tienen sin resolver la raíz de los problemas. Otras características de los modelos de ayuda y bienestar tradicionales incluyen: la fragmentación entre disciplinas y por ende la especialización; la focalización en lo particular fuera de su contexto; la profesionalización y distanciamiento del profesional de ayuda de los ayudados; la conceptualización y el trato de sujetos como objetos (la objetivización); y la conceptualización del profesional de ayuda como tal. (Wallerstain, 1998; Maguire; Ani, 1996; Maguire, 199).

Por otro lado encontramos, luego del impacto del materialismo histórico y las teorías de conf licto, entre otras teorías en las ciencias sociales y la academia, un auge de modelos que denominamos alternativos y los cuales intentan enfocarse en la revolución o cambio social como base del trabajo de profesionales de ayuda. Desde esta conceptualización entonces nuestro trabajo profesional se ha tornado no de ayuda, sino de agente de cambio. Contrario a los modelos tradicionales estos modelos se han caracterizados por su intención de: fomentar el trabajo interdisciplinario; el envolvimiento o acercamiento del "profesional de ayuda" ahora agente de cambio a 
entender la problemática de individuos y comunidades desde la perspectiva de éstos; el reconocimiento de individuos como tales, como sujetos con fortalezas y recursos propios para solucionar sus propios problemas; y la reconceptualización del profesional de ayuda (también con unos poderes y privilegios otorgados por su posición) como posible agente de cambio.

Sin embargo, a pesar de los esfuerzos en el desarrollo de modelos de intervención con individuos y colectivos que fomenten cambios, carecemos de modelos integrales desde donde se pueda estudiar, analizar y evaluar la realidad e interacción entre individuos, colectivos y estructuras a la vez que visualizamos y nos proyectamos hacia la creación de una visión de nuestro bienestar individual y colectivo.

Dada la influencia del pensamiento europeo en el desarrollo tanto de modelos tradicionales como de aquellos alternativos algunos autores argumentan que aún cuando los últimos son un intento por denunciar la opresión sistemática y ofrecer alternativas a ésta, ambos carecen de un entendimiento de la interacción entre las diferentes formas de opresión y su influencia en el desarrollo de nuestra identidad social de grupos, así como de una visión integrada entre las diferentes aspectos de nuestro ser individual y colectivo. Razón por la cual tanto feministas como antiracistas han criticado las limitaciones del materialismo histórico, las teorías de conf licto y la dialéctica desde Marx hasta Freire para explicar la realidad de diferentes grupos oprimidos más allá de la lucha de clases (Ani, 1994; hooks, 1994; Maguire, 1987; Martínez, 1999; Mclaren,1993). Marimba Ani (1994) en una crítica afro-céntrica del pensamiento europeo explica como el pensamiento dicótomo y lineal característico de éste ha influenciado los trabajos que intentan erradicar la opresión aún en el mejor de sus pensadores alternativos. Podríamos pensar que de acuerdo a Ani tanto los modelos tradicionales como aquellos alternativos de origen eurocéntricos son caras de una misma moneda ya que los pensadores sociales europeos no han podido superar su propia ideología de supremacía. Esto a su vez explica por que ponen tanto énfasis en el pensamiento racional por encima de consideraciones de carácter emocional y espiritual, rompiendo así nuestra integridad como seres humanos y deshumanizándonos. A partir de las críticas de Ani, podemos afirmar la necesidad de una transformación al interior de la ideología de supremacía europea en el 
desarrollo de los modelos de bienestar y salud con los cuales estamos más familiarizados.

El modelo de bienestar y desarrollo integral que compartimos aquí precisamente se nutre de la gama de modelos en múltiples disciplinas con base en la filosofía europea así como de modelos y enfoques no-europeos y de origen nativo americano, africanos y asiáticos. A simple vista podemos identificar la influencia de la teoría de conflicto de Marx y Weber, la relación entre conocimiento y poder de Foucault y el sinergismo de Covey. A su vez están presente los trabajos de concientización de Freire, la rueda medicinal nativo americana, el huracán taíno, y el Yin \& Yan asiático. La importancia de cualquier técnica o enfoque para alcanzar nuestro pleno desarrollo y bienestar se encuentra en su efectividad para facilitar procesos de sanación, transformación y liberación dentro de una visión integrada del ser humano y un análisis de las dinámicas de poder. Por ende aquellos que hemos utilizado el modelo hemos incorporado una variedad amplia de "intervenciones" individuales y comunitarias desde técnicas de relajación, meditación y visualización, interpretación de sueños, especificación de metas, confrontaciones, reconocimiento de sentimientos y miedos, "role playing”, modelaje, y auto-diagnósticos; procesos de educación participativa, teatro popular, autogestión comunitaria, desarrollo organizacional y "oratoria" ; hasta música, incienso, rituales, altares, retiros, proyectos de arte, hierbas medicinales y preparación de comidas, entre otros. Como resultado se ha desarrollado un modelo creativo y dinámico de intervención que es a su vez herramienta de análisis y evaluación; guía para un proceso de sanación y transformación individual y colectiva; y una visión integrada del bienestar y el desarrollo de los seres humanos. Esto sin contar que en su sentido gráfico es intelectualmente estimulante y que de tener la oportunidad de elaborarlo tridimencionalmente las posibles implicaciones teóricas podrían ser de carácter físico/metafísico.

Las implicaciones de este modelo a la práctica profesional de ayuda son variadas y aplican a múltiples disciplinas por igual en los campos de la sicología, el trabajo social y la salud. Igualmente pensamos que son de relevancia a los múltiples roles que desempañamos los profesionales de ayuda como: consejeros, facilitadores, investigadores, cabilderos, educadores, organizadores, mentores y agentes de cambio y transformación. Sin embargo, nos limitaremos a discutir solo algunas que consideramos de mayor relevancia. 


\section{La esfera- "no hay principio ni fin"}

Posiblemente lo que parece ser una aportación más evidente de este modelo es precisamente su forma circular lo que nos obliga a re-conceptualizar las necesidades humanas básicas no linealmente en forma piramidal, posicionadas de acuerdo a la ideología europea, sino con la misma distancia de su centro y a fin con los valores de culturas no europeas. Por un lado esto implica que todas las necesidades humanas son de igual importancia y que todas están relacionadas entre sí. La única división que se hace es entre la dimensión individual y la colectiva lo que supone una distancia relativa entre el nivel de influencia del individuo y los colectivos con los cuales éste/a interactua (i.e. familia, comunidad, instituciones, nación, etc.). Por otro lado esto nos lleva a cuestionar si los procesos de transformación tienen un lugar de comienzo y fin, o si podemos empezar por donde las circunstancias e intereses nos lo permitan y partir con la $\mathrm{fe}^{4}$ de que vamos a llegar a donde vamos sabiendo que donde vamos no es el final del camino. Esto no implica que la transformación hacia un estado de bienestar integral no sea alcanzable sino de que al conseguir tal estado para mantenerlo se requiere de seguir caminando unidos, de mantener según Freire (1970) una cultura permanente de "revolución" o transformación. Esto nos lleva, además, a re-evaluar el concepto revolución, concepto que parte de una concepción mecánica de la sociedad y que indica un cambio de los que están "arriba” por aquellos que estamos “abajo”, sin alterar la estructura piramidal/jerárquica original que mantiene la opresión.

Finalmente, la esfera nos da un sentido de conexión entre todas las partes, entre un@s y otr@s, entre todas las dimensiones de nuestro ser individual y colectivo, entre todas nuestras luchas, por ende nos obliga a afirmarnos como seres espirituales conectados entre sí. Como profesionales de ayuda nos obliga a insertarnos dentro del modelo, no fuera de éste, como posibles facilitadores de un procesocon otr@s y para tod@s. Esto a su vez implica que en nuestra práctica tenemos que estar dispuestos a ser fiscalizados y a rendir cuentas sobre nuestras propias contradicciones personales y el uso inadecuado de nuestros privilegios para mantener posiciones de

${ }^{4}$ Certeza que no puede ser científica o empíricamente comprobada. 
poder en especial en relación al conocimiento. Por ejemplo, si como profesionales de ayuda verdaderamente creemos en el poder personal transformativo, entonces tenemos que responder por nuestras adicciones al alcohol y el tabaco, así como por nuestro control de acceso a recursos institucionales e información. A su vez requiere de variar las comunidades con las que podemos trabajar. Estas no solo son los barrios pobres, son también nuestros centros de trabajo, las urbanizaciones donde vivimos, las organizaciones profesionales, los grupos sociales a los que pertenecemos, los partidos políticos, las madres, los que se reúnen a concertar actos de corrupción, las estudiantes, los miembros del crimen organizado, y las heterosexuales, entre muchos más. Muchas son las ocasiones en que los profesionales de ayuda vamos en busca de ayudar a los que viven en comunidades pobres sin embargo, parecen ser menos las veces que utilizamos nuestra influencia en los círculos más cercanos; familiares, amigos, compañeros de trabajo.

\section{El Bienestar- "el bienestar de uno es el bienestar de todos"}

El bienestar del individuo es el bienestar de la colectividad y viceversa. El modelo no se presta para explicar que el bienestar de una persona sea contrario al de los demás, o que este es un mundo donde sobrevive el más fuerte, que por razones prácticas los ricos tienen que vivir de los más pobres, donde el individuo tiene que sacrificarse por la colectividad o vice-versa. El modelo por ser esférico e integral requiere de que se visualice el bienestar como una posibilidad para tod@s. De esta forma el mismo se convierte en una visión que guía nuestra transformación personal y a la que aspiramos para tod@s.

El modelo tampoco coincide con otros modelos y teorías que sostienen que nuestros problemas son producto de nuestra falta de capacidad para manejar el estrés provocado por nuestra incapacidad de adaptarnos o adaptar nuestro medio ambiente (Sermain, 1980). Esto nos obliga a un reenfoque de nuestras prácticas con individuos seamos sicólog@s, trabajadores/as sociales, médicos, etc. Primero, requiere que pensemos en re-enfocar nuestras intervenciones, sean estas medicamentos o terapias, como procesos de sanación de los efectos de años de múltiples formas de opresión internalizada. Por ende, si ante nosotros tenemos una joven, negra, pobre, drogadicta, no podemos enfocarnos estrictamente en 
su problema de adicción sino entender que la misma es la manifestación de años de socialización (incluyendo las de sus ancestros) internalizando miedos y mensajes negativos y deshumanizantes sobre su persona en relación a su condición de clase, género, raza y colonización, y que aún ante esa realidad solo su propia habilidad para responder con conciencia crítica y voluntad intensionada y autodirigida a dichos mensajes la ayudará a sanar los efectos de estas múltiples opresiones y transformar su realidad. Para ello la gama de "intervenciones" que podemos utilizar para facilitar el proceso puede ser tan variada o creativa como sea necesario, desde medicar metadona hasta caminar por el fuego ${ }^{5}$ siempre y cuando sean compatibles con los principios de integridad y transformación del modelo. Esto además implica que debemos redescubrir, recuperar y reutilizar procesos de sanación de origen no europeo, no como cliché o moda "new age" sino como parte de un esfuerzo consciente de que éstos son vitales en nuestra sanación y la recuperación de nuestra humanidad.

Segundo, se hace imperativo la creación de una práctica profesional radical que fomente la conciencia y voluntad colectiva ya que el proceso de transformación no se puede llevar a cabo si no se desmantela intencionalmente la opresión institucional. Por lo tanto, las intervenciones o procesos de sanación individuales, de pareja o de familias están incompletas si no promueven el desarrollo de una conciencia sobre los efectos de la opresión y el privilegio en sus vidas y una voluntad para contribuir a la transformación de nuestra realidad como colectivo. De no hacerlo estamos limitando nuestra capacidad para la transformación. Por otro lado, esto requiere de que estemos conscientes de que las estructuras de poder existentes no han ocurrido por casualidad ni se mantienen por pura coincidencia e inocencia. Se construyeron y son mantenidas por que satisfacen los intereses de los grupos agentes de opresión. Para muchos es claro que la creación de políticas sociales y económicas clasistas, racistas, sexistas, heterosexistas, etc. son creadas con plena conciencia de que perpetúan el poder y el control de los grupos agentes de opresión. Por otro lado, todo aquel que es socialmente identificado como miembro del grupo agente de opresión no puede renunciar a su

5 Caminar por el fuego es un ritual "intervención” que es utilizado para reconocer y combatir el miedo. 
privilegio aún cuando quiera. En otras palabras nosotros, los autores, como personas de tez clara en nuestro país, tenemos que reconocer y responsabilizarnos por nuestro privilegio blanco, ya que no empece a nuestro compromiso por desmantelar el racismo en Puerto Rico gozamos de privilegios que nos son socialmente otorgados.

Finalmente, el modelo ofrece una visión clara de lo que es bienestar integral, que de ser aceptada implicaría un reto tanto a nuestra práctica profesional como a nuestra vida personal, pero a su vez una oportunidad para hacer nuestro trabajo con más dirección y sentido de propósito.

\section{El desarrollo - "desarrollo es un proceso continuo e interactivo"}

Desarrollo en este modelo no es un proceso lineal donde hay un continuo progresivo totalitario que va de salvaje a civilizado, subdesarrollado a desarrollado, o de conciencia ingenua a conciencia crítica. Esto requiere de re-conceptualizar desarrollo como un proceso dinámico, multidimensional e interactivo que surge de la interacción constante entre la dimensión individual y colectiva, los aspectos que componen cada una de éstas y, por el momento, el ciclón de la opresión. De manera que describimos el proceso de desarrollo como la interacción entre múltiples espirales de desarrollo que surgen desde el centro de la esfera hacia afuera y que en la medida en que éstos se logren equilibrar y armonizar en una fuerza unificadora individual y colectiva podremos desmantelar la opresión institucional. Por ende, tenemos que entender que de acuerdo a los recursos y necesidades del momento tanto individuos como colectivos pueden estar desarrollando diferentes aspectos de cada dimensión a distintos niveles en relación a diferentes formas de opresión, pero no es hasta tanto todas éstas se unifiquen que lograremos la transformación. Sin embargo, se hace imprescindible señalar que este desarrollo no es exclusivo de aquellos que son blancos de las diferentes formas de opresión institucional, -1@s pobres, $1 @$ snegr@s, las mujeres, etc.- sino que aquellos miembros de los grupos agentes de opresión requieren también de procesos de sanación, desarrollo y recuperación de su humanidad. Razón por la cual los profesionales de ayuda podemos facilitar procesos de sanación y transformación, pero tenemos que aspirar a la integridad personal para aumentar nuestra efectividad y encontrar nuestro justo lugar en la lucha por la transformación reconociendo que 
solo somos parte de un movimiento mayor y no "salvadores" de los "marginados".

Como proceso de evaluación o diagnóstico de nuestro desarrollo individual o colectivo, el modelo sirve para identificar las necesidades y recursos de cada dimensión y sus respectivos aspectos. Este proceso nos ayuda a identificar, tanto a nivel individual como colectivo, cuáles son las áreas que requieren ser sanadas y fortalecidas en el desarrollo de nuestro poder transformativo auténtico, y de nuestras habilidades para responder a la opresión institucional y reapropiarnos de la humanidad que nos ha sido arrebatada a consecuencia de la institucionalización de un sistema de opresión. A su vez, el mismo puede ser un aporte al desarrollo y formulación de políticas y programas sociales de bienestar ya que sirve para el análisis y la evaluación comprensiva de éstos.

\section{La integridad - "el poder auténtico emerge de la integración de todas las partes pero nunca de ningunas de ellas aisladamente"}

Es necesario plantearse que es tan falso pensar que la adquisición de poder económico resuelve todos nuestros males como colectivo, como los es pensar que lo pueda ser el poder político, social o cultural aisladamente. Obviamente cada una de estas esferas de poder colectivo han jugado un papel determinante tanto en nuestra deshumanización como en nuestra sobrevivencia. Sin embargo, la transformación colectiva no puede darse hasta tanto por un lado se logre el equilibrio entre todos estos cuatro aspectos y por otro que este equilibrio sea armonioso. La armonía es vital en este el proceso de transformación ya que sería inefectivo e ineficiente que los aspectos se contradijeran entre sí. Tómese por ejemplo la lucha entre los valores cristianos y la economía de mercado.

Igualmente falso es la ilusión del poder individual que crean las posiciones de privilegio otorgadas por el poder institucional. En otras palabras, el poder que surge del privilegio no es un poder auténtico por que no surge de la integridad personal sino de la institucionalización de la opresión. El hombre que viola y maltrata a la mujer, o el que hostiga mujeres en el lugar de trabajo no lo hace porque tiene poder personal, sino por que las instituciones le han otorgado el privilegio y le han permitido actuar como agente de opresión aún cuando existan leyes a lo contrario. La opresión individual o el llamado discrimen no existe sin la opresión institucional. De aquí la limitación 
y la trampa de las políticas y leyes anti-discrimen que enfocan la intervención en la criminalización de la conducta del/la agresor/a pero dejan intactas las estructuras de opresión que sostienen y promueven el racismo, sexismo, clasismo y otros "ismos". Por ende, en el caso anterior la problemática del hombre maltratante, violador u hostigador no se puede resolver individualmente sin desmantelar el sexismo institucional. Lo mismo es cierto con toda forma de opresión.

Otras implicaciones que podemos mencionar a cerca del concepto de integridad para nuestro trabajo con comunidades pobres, dado el auge de proyectos de autogestión, sería pensar que el problema de marginación que enfrentan éstas en nuestro país solo serían resueltos a través de la autogestión, sin considerar la importancia fundamental que tienen el equilibrio y la armonía con la esfera política, social y cultural. En otras palabras un verdadero trabajo de autogestión comunitaria o de salud pública tiene que darse a la vez que la comunidad se organiza políticamente para exigir recursos, se fortalecen genuinamente las interrelaciones entre los miembros y se analizan críticamente los valores y principios que guían el trabajo de la comunidad. Igualmente importante es reconocer la importancia que tiene la necesidad de atender de la misma manera todas las necesidades en la dimensión individual (i.e. física, mental, emocional, y espiritual). Como consecuencia necesitamos considerar seriamente, y con mucha más voluntad de la que nuestra retórica proclama, la necesidad de crear espacios y procesos para el trabajo mutlidisciplinario si verdaderamente creemos en la transformación. No hay razón por la cual no podamos trabajar coordinada y efectivamente trabajadores/as sociales, sicólog@s, médicos, artistas y economistas, por nombrar algunos. Inclusive para que estudiantes universitarios hagan prácticas y trabajos de tesis en equipos multidisciplinarios.

Por otro lado, así como la integridad requiere de equilibrio y armonía entre todas los aspectos de la dimensión individual y colectiva, requiere además del reconocimiento de nuestras múltiples identidades sociales tanto como agentes de opresión como blancos de éstas. Por ende es indispensable que analicemos para nosotr@s mism@s y facilitemos el que otr@s analicen los efectos tanto de nuestra opresión internalizada como de nuestros privilegios internalizados. Esto nos plantea la necesidad de promover el que las personas en todo tipo de grupo reconozcan sus privilegios en rela- 
ción a cada miembro del grupo así como las conductas que son producto de nuestra opresión internalizada en el grupo. Por ejemplo, en un grupo comunitario organizado con el propósito de promover la autogestión es necesario que los hombres del grupo se planteen el impacto del privilegio de género como hombres en relación a las mujeres, como es igualmente importante que las mujeres trabajen con su internalización de los valores sexistas. Lo mismo se da en terapias de familias o en la relación entre médico y paciente. Esto reconociendo que se requiere de crear un nivel de confianza y un proceso adecuado para promover el que se hagan estas conexiones. En dicho caso es también importante que el/la el profesional de ayuda reconozca sus privilegios y el impacto en el/ella de la opresión internalizada.

A su vez, las dinámicas de opresión entre individuos nos plantea la necesidad de reconocer la limitación y el efecto contraproducente que tiene el trabajar con opresiones aisladamente con la falsa noción de que si luchamos en contra de una luego podemos erradicar la otra. Dos ejemplos de gran impacto según nuestra perspectiva son el racismo y el sexismo en las organizaciones y movimientos de descolonización en Puerto Rico, y la falta de una estrategia efectiva en contra del maltrato de menores en los movimientos feministas que liderean la lucha en contra de la violencia doméstica. En ambos casos hemos pecado de ignorar o dejar en un segundo plano formas de opresión que van de la mano y de no entender la dificultad en poder propiciar el desmantelamiento de una forma de opresión en particular sin entender la conexión entre todas, más aún si no fomentamos su desmantelamiento al menos dentro de nuestras organizaciones y movimientos.

Finalmente, la integridad nos ayuda a reconceptualizar el concepto poder, en este caso el poder transformativo auténtico. Primero, reconocer que surge de la integridad -del equilibrio y la armonía entre todas las partes-, y segundo que este balance y armonía solo lo logramos individual y colectivamente a través de nuestra conciencia y voluntad individual, colectiva y divina. Esta última dada por el reconocimiento del modelo del carácter espiritual de los seres humanos. Como consecuencia la integridad pasa a ocupar un lugar central tanto en nuestro desarrollo personal como en nuestra práctica profesional y en lo que aspiramos para tod@s. Vivir con integridad se convertirá en la fuerza, el poder, que propulsará nuestra transformación individual y colectiva. 
Algunas de la implicaciones discutidas no son exclusivas de este modelo y tampoco son nuevas discusiones en el campo de la salud y las ciencias sociales, las mismas han sido planteadas en relación a nuevas conceptualizaciones de las profesiones en estos campos. Sin embargo, aquí se recogen dentro de un mismo modelo de bienestar y desarrollo y se re-plantean partiendo del concepto integridad. Otras aspectos de relevancia que esperamos discutir con más profundidad en trabajos subsiguientes son la implicaciones para el campo de la investigación social, el desarrollo de liderato, los issues de fiscalización/rendir cuentas (accountibility) a la comunidad, y el rol del profesional de ayuda como padrino/madrina (gate keeper).

\section{A manera de Comentario}

A través de este trabajo hemos querido compartir los modelos más importantes que integran un modelo de bienestar y desarrollo integral, los cuales hemos venido desarrollando y utilizando por casi diez años en nuestros trabajos de organización comunitaria. El mismo es el producto de un trabajo colectivo con otr@s compañeras/os y en el cual hemos tenido la oportunidad de participar activamente en el proceso creativo, en la integración de conceptos, la documentación, la elaboración de diagramas y mapas conceptuales y la auto-evaluación del mismo. Esperamos que este primer intento de compartirlo ampliamente sirva para que continuemos el desarrollo y la evolución de éste a través de la experiencia y las contribuciones de otros profesionales de ayuda y trabajadores comunitarios comprometidos con la justicia y el bienestar social.

\section{Bibliografía}

Akbar, Na'im (1996). Breaking the Chains of Psychological Slavery. New Jersey: Mind Productions.

Ani, Marimba (1996). YURUGU: An African-Centered Critigues of European Cultural Thought and Behavior. New Jersey: Africa World Press.

Ani, Marimba (1994). Yuguru: An African-Centered Critique of European Cultural Thought and Behavior. New Jersey: Africa World Press, Inc. 
Assagioli, Roberto (1976). Psychosynthesis. New York: Penguin Books. Assagioli, Roberto (1973). The Act of Will. New York: Penguin Books. Bopp, Judie; Bopp, Michael; Lane, Phil; Brown, Lee (1988). The Sacred Tree: Reflections on Native American Spirituality. Alberta, Canada: Four Worlds Development Press.

Bulhan, Hussein Abdilahi (1985). Frantz Fanon and the Psychology of Oppresion. New York: Plenum Press.

Chisom, Ronald, y Michael Washington (1997) Undoing Racism: A Philosophy for International Social Change. Lousiana: The People's Institute Press.

Fanon, Frantz (1963). The Wretched of the Earth. New York: Grove Weidenfeld.

Freire, Paolo (1970). Pedagogía del oprimido. México: Siglo Veintiuno Editores.

Freire, Paulo (1970). Cultural action and conscientization, Harvard Educational Review, 40(3), 452-477.

Gil, David (1992). Unravelling Social Policy, 5th. Edition. Vermont: Schenkman Books.

Gil, David (1993). Confronting oppression and social injustice In F. Reamer (Ed.) The Foundation of Social Work Knowledge. New York: Colombia University Press.

Hooks, Bell (1984). Feminist Theory: from margin to center. Massachusetts: South End Press.

Hooks, Bell (1993). Sisters of the Yam: Black Women and Self-Recovery. Boston: South End Press.

Lörler, Marie-Lu (1992). Shamanic Healing within the Medicine Wheel. Albuquerque, N.M.: Brotherhood of Life.

Maguire, Patricia (1987). Doing Participatory Research: a feminist approach. Massachusetts: The Center for International Education, School of Education, University of Massachusetts.

Martín-Baró, Ignacio (1994). Writings for a Liberation Psychology. (Adrianne Aron and Shawn Corne, eds.). Cambridge, MA: Harvard Univesity Press.

Martínez Ramos, Loyda M. (1999:22) La pedagogía de la liberación desde una perspectiva de género. Diálogo, diciembre.

Memmi, Albert (2000). Racism. Minnrspolis: University of Minnesota Press.

Quiñones Rosado, Raúl (1995). Manual de entrenamiento de mentores. Springfield, MA: Gándara Mental Health Center \& Dunbar Community Center. 
Schipani, David S. and P. Freire (1992). Educación, Libertad y Creatividad: encuentro y diálogo con Paulo Freire. San Juan, PR: Universidad Interamericana de Puerto Rico.

Wallerstain, Immanuel (1998) Abrir las ciencias sociales: Informe de la Comisión Gulbenkian para la reestrucuración de las ciencias sociales. México: Siglo Veintiuno Editores, S.A. de C.V.

Wilbur, Ken (1977). The Spectrum of Consciousnes. Wheaton, IL: The Theosophical Publishing House. 